\title{
DNA methylation analysis of selected genes for the detection of early-stage lung cancer using circulating cell-free DNA
}

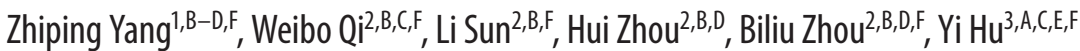 \\ ${ }^{1}$ Department of Oncology, The First Affiliated Hospital of Jiaxing University, Zhejiang, China \\ 2 Department of Clinical Laboratory, The First Affiliated Hospital of Jiaxing University, Zhejiang, China \\ ${ }^{3}$ Department of Chest Surgery, The First Affiliated Hospital of Jiaxing University, Zhejiang, China \\ A - research concept and design; B - collection and/or assembly of data; $\mathrm{C}$ - data analysis and interpretation; \\ $D$ - writing the article; $E$ - critical revision of the article; $F$ - final approval of the article
}

\author{
Address for correspondence \\ YiHu \\ E-mail:jxhy7616@163.com \\ Funding sources \\ None declared \\ Conflict of interest \\ None declared

\section{Acknowledgements} \\ This study was supported by the Project of Research \\ and Demonstration Applications in Social Development \\ Jiaxing, China (2015AY23018) and a research fund \\ from the Jiaxing Innovation Team of Early Diagnosis \\ and Comprehensive Therapy for Lung Cancer.
}

Received on July 12, 2017

Reviewed on November 6, 2017

Accepted on January 31,2018

Published online on December 5, 2018

Cite as

Yang Z, Oi W, Sun L, Zhou H, Zhou B, Hu Y. DNA methylation analysis of selected genes for the detection of early-stage lung cancer using circulating cell-free DNA. Adv Clin Exp Med. 2019;28(3):355-360. doi:10.17219/acem/84935

DOI

10.17219/acem/84935

\section{Copyright}

Copyright by Author(s)

This is an article distributed under the terms of the

Creative Commons Attribution Non-Commercial License

(http://creativecommons.org/licenses/by-nc-nd/4.0/)

\section{Abstract}

Background. Lung cancer is still the deadliest cancer in the world, but early diagnosis cannot be achieved because of the limitations of diagnostic methods. DNA methylation has been proven to be a potentially powerful tool for cancer detection and diagnosis over the past decade.

Objectives. We explored whether free DNA methylation in plasma can be a reliable biomarker for noninvasive lung cancer detection.

Material and methods. We detected the methylation of 8 genes in plasma-free DNA of patients with pulmonary space-occupying lesions using real-time quantitative methylation-specific polymerase chain reaction (QMSP). Among the 50 selected patients, 39 were confirmed using pathological analysis as having early lung cancer and 11 had an inflammatory pseudotumor.

Results. The QMSP detection showed that the methylation levels of 8 genes in the patients were significantly higher than in the non-lung cancer group. The methylation level of CALCA was the highest and the methylation level of HOXA9 was the lowest. Methylation of RASSFTA, CDKN2A and DLEC1 occured only in lung cancer patients, while methylation of CALCA, CDH13, PITX2, HOXA9, and WT1 occured not only in lung cancer patients, but also in non-lung cancers. The specificity reached $95 \sim 100 \%$, whether for a single gene or overall, but the sensitivity was relatively low for each gene. The sensitivity can reach $72 \%$ if the methylation of any of the 8 genes is positive and the overall specificity was $91 \%$. The positive and negative predictive values were $96 \%$ and $60 \%$, respectively.

Conclusions. Quantitative detection of DNA methylation in plasma is a potential method for early diagnosis of lung cancer.

Key words: lung cancer, early diagnosis, QSMP, plasma-free DNA 


\section{Introduction}

The lung cancer mortality is $19.4 \%$; it accounts for $22.83 \%$ of all male tumors, while its incidence rate in female tumors is $14.32 \% .{ }^{1}$ The 5 -year survival rate of patients with stage I lung cancer is $60-90 \%$, while it is only $5-20 \%$ in patients with stage IIIb and stage IV. ${ }^{2}$ Most lung cancers are detected in middle and late stages due to the lack of effective diagnostic methods. Therefore, early detection and treatment of lung cancer play an important role in controlling its mortality. Chest radiography and sputum cytology are economical and practical methods in current early screening methods; however, their sensitivity and specificity are not very high. Lowdose computed tomography $(\mathrm{CT})$ can detect small lesions of only a few millimeters in the lung and its sensitivity is high, but the specificity is poor; it can also cause a mental and financial burden to patients with benign tumor nodules, and may even inflict unnecessary trauma to their bodies. ${ }^{3}$

DNA methylation is an important epigenetic phenomenon that can affect gene expression without changing the DNA sequence. Aberrant methylation of the promoter 5'-C-phosphate-G-3' (CpG) island leads to silencing of tumor suppressor genes, which is one of the important mechanisms of tumorigenesis. ${ }^{4}$ Studies have shown that DNA abnormal methylation exists before the patient shows clinical symptoms or before X-ray evidence is obtainable. Moreover, it exists in many bodily fluids such as plasma, urine, semen, and feces. ${ }^{5-7}$ These findings suggest that DNA methylation may serve as a biomarker for noninvasive diagnosis, and is useful in the early diagnosis of cancer. Methylation of the $C A L C A$, HOXA9 and PITX2 genes is an effective biomarker for lung cancer. ${ }^{8-11}$ However, the sensitivity of single gene methylation detection is only about $60 \%$, which fails to meet the standard for early diagnosis of lung cancer. One study found that the combined detection of multigene methylation can increase the sensitivity to $93 \%$, but the specificity is decreased. ${ }^{12}$ Even so, the concentration and integrity of free DNA in patients with cancer are higher than in healthy subjects, and detecting the methylation of lung cancer-associated genes by extracting free DNA in plasma is the trend in the early diagnosis of lung cancer in recent years.

In this study, the methylation of 8 genes $(C D H 13$, WT1, CDKN2A, HOXA9, PITX2, CALCA, RASSF1A, and $D L E C 1)$ in plasma was analyzed by fluorescent realtime quantitative methylation-specific polymerase chain reaction (QMSP), and the results of a histopathological diagnosis and gene methylation were compared and analyzed. We determined whether free DNA methylation in plasma can be a reliable biomarker for noninvasive lung cancer detection, which could provide clinical data support for free DNA methylation as a biomarker for large-scale early noninvasive screening of lung cancer.

\section{Material and methods}

\section{Subjects}

A total of 50 patients with pulmonary space-occupying lesions found using chest CT who underwent surgery in the First Affiliated Hospital of Jiaxing University, Zhejiang, China, between June 2015 and June 2017 were enrolled into the study. The selected patients met the following criteria:

- chest CT suggested radiographic abnormalities with pulmonary space-occupying lesions, including nodules and masses 5-20 $\mathrm{mm}$ in size;

- absence of related antineoplastic treatments such as surgery, chemotherapy, radiotherapy, targeted therapy, or biological immunotherapy;

- absence of diseases not suitable for venous blood collection, such as blood diseases and acute infectious diseases that can be transmitted by blood.

Patients with lung cancer recurrence, accompanied by other malignancies, pregnant or breast-feeding women, and patients with autoimmune diseases were excluded. The demographic characteristic of the patients is shown in Table 1.

The study protocol was reviewed and approved by the Research Ethics Committee of the hospital. Written informed consent was obtained from each of the participants or their legal guardians.

\section{Pathological features}

The lung tissue was resected surgically and fixed with $4 \%$ paraformaldehyde to prepare paraffin sections and hematoxylin and eosin (H\&E) staining. Lung cancer was diagnosed by 2 experienced pathology experts. A total of 39 cases of stage I lung cancer were identified by pathological analysis among the 50 selected cases, which included 25 cases of adenocarcinoma, 12 cases of squamous cell carcinoma and 2 cases of mucinous carcinoma. The remaining 11 cases were inflammatory pseudotumors.

Table 1. Comparison of demographic characteristics of the 2 groups

\begin{tabular}{|l|c|c|c|}
\hline \multicolumn{1}{|c|}{ Variables } & $\begin{array}{c}\text { Lung cancer } \\
\text { patients } \\
(\mathrm{n}=39)\end{array}$ & $\begin{array}{c}\text { Non-lung cancer } \\
\text { patients } \\
(\mathrm{n}=11)\end{array}$ & p-value \\
\hline $\begin{array}{l}\text { Gender (\%) } \\
\text { male } \\
\text { female }\end{array}$ & $24(61.5)$ & $7(63.6)$ & 0.09 \\
\hline Age (mean + SD) & $51 \pm 11.62$ & $4(36.4)$ & 0.11 \\
\hline $\begin{array}{l}\text { Smoking status (\%) } \\
\text { smokers } \\
\text { non-smokers }\end{array}$ & $29(74.4)$ & $8(72.7)$ & 0.29 \\
\hline Stage I of pTNM (\%) & $39(105.6)$ & $3(27.3)$ & - \\
\hline
\end{tabular}

SD - standard deviation; PTNM - TNM Classification of Malignant Tumours (tumour-node-metastasis) based on histopathologic examination of a surgical specimen. 


\section{Plasma DNA extraction}

Samples of anticoagulant peripheral blood were collected before the operation and plasma was separated by centrifugation at $1000 \mathrm{rpm}$ for $10 \mathrm{~min}$. The isolated plasma was cryopreserved at $-80^{\circ} \mathrm{C}$ for the extraction of plasma-free DNA and used for methylation detection.

The DNA was extracted from $500 \mu \mathrm{L}$ of plasma of the subjects using a QIAamp MinElute Virus Spin Kit (Qiagen, Hilden, Germany), according to the manufacturer's instructions. The extracted DNA was amplified using a GAPDH gene primer (F: AGGTCGGAGTCAACGGATTTG, R: GTGATGGCATGGACTGTGGT). The conditions for the PCR were as follows: $5 \mathrm{~min}$ at $95^{\circ} \mathrm{C}$, then $15 \mathrm{~s}$ at $95^{\circ} \mathrm{C}$, $30 \mathrm{~s}$ at $60^{\circ} \mathrm{C}, 30 \mathrm{~s}$ at $72^{\circ} \mathrm{C}$ for 38 cycles, and finally $10 \mathrm{~min}$ at $72^{\circ} \mathrm{C}$. Polymerase chain reaction amplification products were observed after $2 \%$ agarose gel electrophoresis using ImageQuant LAS 4000 (GE Healthcare Life Sciences, Marlborough, USA) gel imaging system, and the specimens not amplified for the desired PCR product were eliminated.

\section{DNA modified by sodium bisulfite}

Plasma-free DNA was modified by sodium bisulfite using an EpiTect Bisulfite Kit (Qiagen), according to the manufacturer's instructions. DNA $(1 \mu \mathrm{g})$ was added to Bisulfite Mix Solutions (85 $\mu \mathrm{L}$; Qiagen) and DNA Protect Buffer (35 $\mu \mathrm{L}$; Qiagen) - the final volume was $140 \mu \mathrm{L}$ - by adding RNase-free water. They were incubated at $60^{\circ} \mathrm{C}$ for $5 \mathrm{~h}$, then heated to $95^{\circ} \mathrm{C}$ and rapidly quenched in an ice bath. The single-stranded DNA solution was purified by an EpiTect Spin Column (Qiagen) and DNA modified by sodium bisulfite was obtained.

\section{Real-time quantitative methylation-specific polymerase chain reaction}

The modified DNA was amplified using real-time quantitative methylation-specific PCR (QMSP) as described by Nawaz et al. ${ }^{12}$ The target genes included CDH13, WT1, CDKN2A, HOXA9, PITX2, CALCA, RASSF1A, and $D L E C 1$. The relative methylation level of the target genes was determined with $\beta$-actin as a reference gene. The sequences of primers and probes used in this study are shown in Table 2. The QMSP reaction system contained $600 \mathrm{nM}$ of primers, $200 \mathrm{nM}$ of probe, $0.75 \mathrm{U}$ of platinum Taq polymerase, $200 \mathrm{mM}$ of deoxyribonucleotide triphosphate (dNTP), $16.6 \mathrm{mM}$ of ammonium sulphate, $67 \mathrm{mM}$ of Tris, $6.7 \mathrm{mM}$ of magnesium chloride $\left(\mathrm{MgCl}_{2}\right), 10 \mathrm{mM}$ of mercaptoethanol, $0.5 \mu \mathrm{L}$ of $0.1 \%$ dimethyl sulfoxide (DMSO), and $50 \mathrm{ng}$ of modified DNA.

The conditions for the QMSP reaction were as follows: $1 \mathrm{~min}$ at $95^{\circ} \mathrm{C} ; 15 \mathrm{~s}$ at $95^{\circ} \mathrm{C}$ and $1 \mathrm{~min}$ at $60^{\circ} \mathrm{C}$ for 50 cycles. DNA of healthy human leukocytes treated with Sss I methylase (New England Biolabs, Inc., Ipswich, USA) was used as a positive control.

\section{Statistical analysis}

The SPSS v. 19.0 software (IBM Corp., Armonk, USA) was used for statistical analysis. The association between the pathological features and the demographic characteristics was evaluated with a $\chi^{2}$ test. The level of statistical difference was defined at 0.05 . The sensitivity and specificity of plasma DNA methylation level detection to diagnose lung cancer were calculated. Sensitivity was positive for positive methylation/total cancer cases and specificity was negative for negative methylation/total benign cases.

\section{Results}

The QMSP results showed that the methylation levels of 8 genes in 39 lung cancer patients were significantly higher than those in the non-lung cancer group. The methylation level of $C A L C A$ gene was the highest, followed by CDH13, RASSF1A, DLEC1, WT1, CDKN2A, and PITX2, and the methylation level of $H O X A 9$ gene was the lowest. Methylation of RASSF1A, CDKN2A and DLEC1 occurred only in lung cancer patients, while the methylation of $C A L$ CA, CDH13, PITX2, HOXA9, and WT1 occurred not only in lung cancer patients, but also in benign lung patients. Methylation levels of each gene in lung cancer and nonlung cancer patients are shown in Fig. 1 and Table 3.

Table 2. QMSP primer and probe sequences

\begin{tabular}{|c|c|c|}
\hline Genes & Primer sequence $\left(5^{\prime}-3^{\prime}\right)$ & $\begin{array}{c}\text { Probe sequence }\left(5^{\prime}-3^{\prime}\right) 6 \text { FAM-DNA } \\
\text { sequences-6TAMRA }\end{array}$ \\
\hline$\beta$-Actin & $\begin{array}{l}\text { F: TGGTGATGGAGGAGGTTTAGTAAG T } \\
\text { R:AACCAATAAAACCTACTCCTCCCTTAA }\end{array}$ & ACCACCACCCAACACACAATAACAAAC ACA \\
\hline $\mathrm{CDH} 13$ & $\begin{array}{l}\text { F: TCGCGGGGTTCGTTTTTCGC } \\
\text { R: GACGTTTTCATTCATACACGCG }\end{array}$ & CGCCCACCCGACCTCGCA T \\
\hline WT1 & $\begin{array}{l}\text { F:GCGTCGGAGGTTAAGGTTGTT } \\
\text { R: CTCTCCAAAATTACCGTACGCG }\end{array}$ & AACTCGCTCGCCCGCCGAA \\
\hline HOXA9 & $\begin{array}{c}\text { F: TTTAGGGTTTTAGTGGTGGTTAT } \\
\text { R: TTCCCCCCCCATACCACCAAATTATTACA }\end{array}$ & AATTATTACATAAAATCTACAATT \\
\hline PITX2 & $\begin{array}{c}\text { F: GGATAGTCGGATCGAGTTAACGTC } \\
\text { R: CCCTCCCAAACGCCGA }\end{array}$ & TTCGGTAATTCGTAGCGGTAGGGTTTGG \\
\hline CALCA & $\begin{array}{c}\text { F: GTTTTGGAAGTATGAGGGTGACG } \\
\text { R: TTCCCGCCGCTATAAATCG }\end{array}$ & ATTCCGCCAATACACAACAACCAATAAACG \\
\hline RASSFIA & $\begin{array}{c}\text { F: GGGATTAGAATTTTTTATGCGAGTTGT } \\
\text { R: TACCCCGACGATACCCAAAC }\end{array}$ & TGTCGAGAACGCGAGCGATTCG \\
\hline DLEC1 & $\begin{array}{l}\text { F: GGTTTGTTAAAAGGGGATGT } \\
\text { R: ACACCCTCCCCCCCTTAAT }\end{array}$ & GTTTTATAATATTTGGGATTGA \\
\hline CDKN2A & $\begin{array}{l}\text { F: TTATTAGAGGGTGGGGCGGATCGC } \\
\text { R: GACCCCGAACCGCGACCGTAA }\end{array}$ & TAACTAAAAATTCACCTACCGAC \\
\hline
\end{tabular}


Quantitative methylation tests results were compared with histopathological findings, and the specificity and sensitivity of the detection of plasma-free DNA methylation levels in the diagnosis of lung cancer were determined. As shown in Table 4, the specificity reached 95 100\%, whether for a single gene or overall, but the sensitivity was relatively low for each gene. The sensitivity can reach $72 \%$ if the methylation of any of the 8 genes is positive and the overall specificity was $91 \%$. The positive and negative predictive values were $96 \%$ and $60 \%$, respectively.

\section{Discussion}

Lung cancer mortality has decreased by $20 \%$ due to the widespread use of low-dose CT screening recently. ${ }^{1-3}$ This technique may be the main method for the diagnosis of lung cancer in the future, and more patients with earlystage lung cancer will be diagnosed. ${ }^{3}$ However, low-dose CT screening cannot distinguish lung cancer from benign lung lesions. Therefore, in this study, we used the QMSP technique to detect the methylation levels of 8 genes (WT1, CDKN2A, HOXA9, PITX2, CALCA, RASSF1A, CDH13, and $D L E C 1)$ in the plasma-free DNA of lung cancer-affected patients diagnosed by low-dose CT screening. The results were compared with the pathological results of lung tissue to observe whether the level of plasma-free DNA methylation could be used for the diagnosis of early lung cancer.

DNA methylation is common in human cancers; it has been observed that methylated DNA can enter the plasma from cancer cells, and methylation of DNA in plasma suggests the presence of cancer. ${ }^{14-17}$ DNA has a stable molecular structure and provides better detection stability. DNA methylation can be accurately quantified using qPCR analysis. In this study, we detected the methylation of 8 genes in the plasma-free DNA of patients with pulmonary space-occupying lesions using QMSP. It was found that there were significant differences in the methylation levels of the 8 genes in lung cancer and non-lung cancer patients. Different levels of plasma DNA methylation can be detected in $70 \%$ of lung cancer patients. Compared to the regression analysis results of pathology, the specificity of the diagnosis of lung cancer reached $95 \sim 100 \%$ with the analysis of the plasma DNA methylation level of 8 genes. DNA methylation may be a molecular marker for the early diagnosis of lung cancer.

The CDH13 gene is one of the members of the cadherin gene family. It is a tumor suppressor gene. Its expression is reduced or absent in a variety of tumors. The methylation of the $C D H 13$ promoter is the major cause of its downregulation. ${ }^{18}$

The WT1 gene encodes human Wilms tumor protein; it is a transcriptional regulatory factor that has a bidirectional regulatory effect on cancer. Hypermethylation and overexpression of WT1 gene are present in many tumors. ${ }^{19}$

CDKN2A encodes p16 protein and is also an important tumor suppressor gene; it belongs to the cyclin-dependent kinase inhibitory factor family. The CDKN2A gene plays a negative regulatory role in the cell cycle. It causes the cell cycle to stagnate at the G1/S phase by inhibiting the activity of cyclin-dependent kinases 4 and 6. CDKN2A methylation levels increase in a variety of malignancies. ${ }^{20}$

The HOXA9 gene is a member of the homeobox (HOX) gene family. Its protein is an important transcription regulator, which plays an important role in controlling embryonic development and regulating cell differentiation. The methylation of the HOXA9 promoter and its abnormal expression are closely related to acute leukemia, malignant glioma, ovarian cancer, lung cancer, and breast cancer. ${ }^{9}$

PITX2 belongs to the transcription factor of the pairedbicoid protein family. It plays an important role in embryonic development and is abnormally expressed in breast cancer, nonfunctional pituitary adenoma, nephroblastoma, and colorectal cancer. ${ }^{21}$

$C A L C A$ is a polypeptide secreted by the parathyroid gland and forms a complex with calcitonin. It has been found that elevated levels of CALCA promoter methylation
Table 3. Positive rate of plasma DNA methylation in patients

\begin{tabular}{|l|c|c|}
\multicolumn{1}{|c|}{ Genes } & Lung cancer* & Non-lung cancer* \\
\hline CDH13 & $66.7(26 / 39)$ & $27.3(3 / 11)$ \\
\hline WT1 & $30.8(12 / 39)$ & $0(0 / 11)$ \\
\hline CDKN2A & $28.2(11 / 39)$ & $0(0 / 11)$ \\
\hline HOXA9 & $20.5(8 / 39)$ & $9.1(1 / 11)$ \\
\hline PITX2 & $28.2(11 / 39)$ & $9.1(1 / 11)$ \\
\hline CALCA & $84.6(33 / 39)$ & $45.5(5 / 11)$ \\
\hline RASSF1A & $41.0(16 / 39)$ & $0(0 / 11)$ \\
\hline DLEC1 & $41.0(16 / 39)$ & $0(0 / 11)$ \\
\hline All 8 genes & $94.9(37 / 39)$ & $63.6(7 / 11)$ \\
\hline
\end{tabular}

*\% (number of methylation-positive cases/total number of cases).
Table 4. Specificity and sensitivity of DNA methylation in diagnosis of lung cancer

\begin{tabular}{|l|c|c|c|c|c|}
\multirow{2}{*}{ Genes } & \multirow{2}{*}{ Sensitivity } & Specificity & Cut-off & \multicolumn{2}{|c}{ Ranges of methylation } \\
\cline { 5 - 6 } & & & values & lung cancer & non-lung cancer \\
\hline CDH13 & $31(12 / 39)$ & $91(10 / 11)$ & 18.0 & $0.000-75.513$ & $0.000-26.912$ \\
\hline WT1 & $31(12 / 39)$ & $100(11 / 11)$ & 0.0 & $0.000-181.576$ & $0.000-0.000$ \\
\hline CDKN2A & $28(11 / 39)$ & $100(11 / 11)$ & 0.0 & $0.000-21.321$ & $0.000-0.000$ \\
\hline HOXA9 & $21(8 / 39)$ & $100(11 / 11)$ & 3.1 & $0.000-39.405$ & $0.000-3.041$ \\
\hline PITX2 & $28(11 / 39)$ & $100(11 / 11)$ & 2.0 & $0.000-19.059$ & $0.000-1.811$ \\
\hline CALCA & $51(20 / 39)$ & $100(11 / 11)$ & 38.0 & $0.000-425.447$ & $0.000-37.004$ \\
\hline RASSF1A & $41(16 / 39)$ & $100(11 / 11)$ & 0.0 & $0.000-19.059$ & $0.000-0.000$ \\
\hline DLEC1 & $41(16 / 39)$ & $100(11 / 11)$ & 0.0 & $0.000-24.146$ & $0.000-0.000$ \\
\hline All 8 genes & $72(28 / 39)$ & $91(10 / 11)$ & N/A & N/A & N/A \\
\hline
\end{tabular}

N/A - not applicable; \% (number of methylation-positive cases/total number of cancer cases); specificity: \% (number of methylation-negative cases/total number of benign cases). 

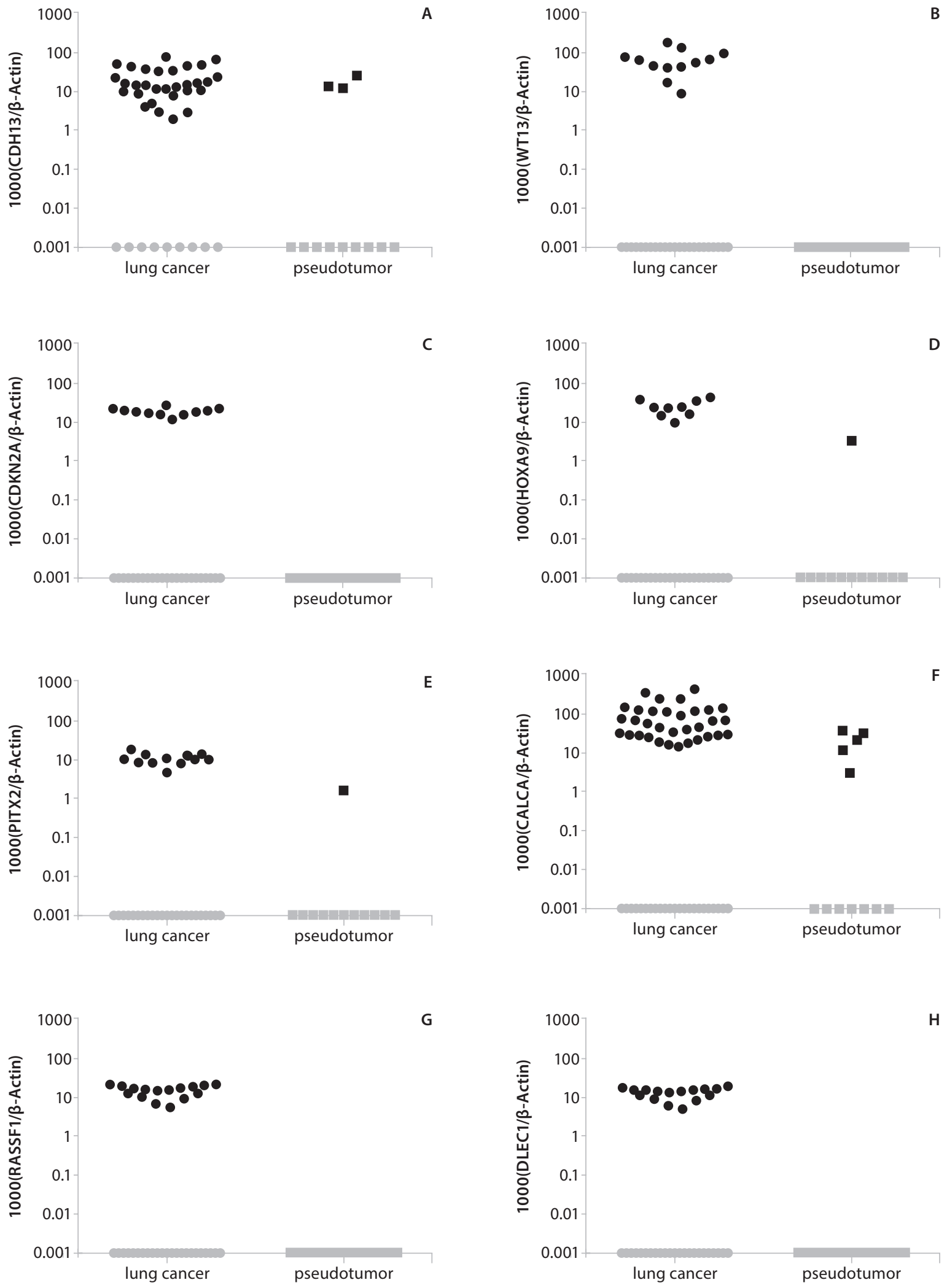

Fig. 1. Comparison of plasma DNA methylation levels of 8 genes in patients with lung cancer and without lung cancer. The methylation level of $C A L C A$ was the highest, followed by CDH13, RASSF1A, DLEC1, WT1, CDKN2A, and PITX2, while the methylation level of HOXA9 was the lowest in patients. Methylation of RASSF1A, CDKN2A and DLECI occurred only in lung cancer patients 
may be an important marker of malignant tumors such as esophageal cancer, colon cancer and thyroid cancer. ${ }^{22}$

RASSF $1 A$ is a novel tumor suppressor gene cloned from the short arm of human chromosome 3. It is low-expressed or not expressed in various tumor tissues. The reason for its nonexpression may be the specific methylation of $\mathrm{CpG}$ island in the promoter region. ${ }^{23} \mathrm{DLEC1}$ is a tumor suppressor gene located at the $3 \mathrm{p} 21.3$ region. It can inhibit the growth of lung cancer, esophageal cancer and the renal carcinoma cell line. The specific methylation of $\mathrm{CpG}$ island in the promoter region can cause downregulation or nonexpression of $D L E C 1$, which is associated with the development of multiple tumors. ${ }^{24}$

It has been shown that the methylation of $C D K N 2 A$, RASSF1A, APC, RAR $\beta, D L E C 1, D A P K$, and $C D H 13$ genes in peripheral plasma-free DNA may be a potential marker for the diagnosis of lung cancer. ${ }^{25,26}$ The methylation of $C D$ $K N 2 A$ and RASSF1A are also associated with the prognosis of lung cancer. ${ }^{8,27}$ The methylation of these genes has good sensitivity and specificity in lung cancer. ${ }^{23,28}$ Our results showed that there were significant differences in the methylation levels of the 8 genes between lung cancer patients and non-lung cancer patients. Methylation of RASSF1A, $C D K N 2 A$ and DLEC1 occurred only in lung cancer patients, while the methylation of CALCA, CDH13, PITX2, HOXA9, and WT1 occurred not only in lung cancer patients, but also in non-lung cancer patients. The sensitivity and specificity of methylation detection of these 8 genes in the diagnosis of lung cancer are lower than those reported in other studies. This may be due to the fact that all the subjects examined in this study are stage I lung cancer patients, or due to the small sample size.

We explored the utility of quantitative detection of plasma DNA methylation in the diagnosis of early lung cancer. The distinction between early lung cancer and benign lung lesions is highly specific and sensitive by detecting the methylation levels of 8 genes. This study also showed that the accuracy of the detection is increased with the increase of the number of detection genes; therefore, finding more and more meaningful markers will also be an important task in further studies. It was found that quantitative detection of DNA methylation in plasma is a potential method for early diagnosis of lung cancer.

\section{References}

1. Carter D. New global survey shows an increasing cancer burden. Am J Nurs. 2014;114(3):17.

2. Nardi-Agmon I, Peled N. Exhaled breath analysis for the early detection of lung cancer: Recent developments and future prospects. Lung Cancer (Auckl). 2017;8:31-38.

3. Fujikawa A, Takiguchi Y, Mizuno S, et al. Lung cancer screening: Comparison of computed tomography and X-ray. Lung Cancer. 2008;61(2):195-201.

4. Das PM, Singal R. DNA methylation and cancer. J Clin Oncol. 2004;22(22):4632-4642.

5. Agostini M, Pucciarelli S, Enzo MV, et al. Circulating cell-free DNA: A promising marker of pathologic tumor response in rectal cancer patients receiving preoperative chemoradiotherapy. Ann Surg Oncol. 2011;18(9):2461-2468.
6. Anker P, Lyautey J, Lederrey C, Stroun M. Circulating nucleic acids in plasma or serum. Clin Chim Acta. 2001;313(1-2):143-146.

7. De Mattos-Arruda L, Olmos D, Tabernero J. Prognostic and predictive roles for circulating biomarkers in gastrointestinal cancer. Future Oncol. 2011;7(12):1385-1397.

8. Lou-Qian Z, Rong Y, Ming L, Xin Y, Feng J, Lin X. The prognostic value of epigenetic silencing of p16 gene in NSCLC patients: A systematic review and meta-analysis. PLoS One. 2013;8(1):e54970.

9. Hwang JA, Lee BB, Kim Y, et al. HOXA9 inhibits migration of lung cancer cells and its hypermethylation is associated with recurrence in non-small cell lung cancer. Mol Carcinog. 2015;54(Suppl 1):E72-80.

10. Dietrich D, Hasinger O, Liebenberg V, Field JK, Kristiansen G, Soltermann A. DNA methylation of the homeobox genes PITX2 and SHOX2 predicts outcome in non-small-cell lung cancer patients. Diagn Mol Pathol. 2012;21(2):93-104.

11. Wrangle J, Machida EO, Danilova L, et al. Functional identification of cancer-specific methylation of CDO1, HOXA9 and TAC1 for the diagnosis of lung cancer. Clin Cancer Res. 2014;20(7):1856-1864.

12. Nawaz I, Qiu X, Wu H, et al. Development of a multiplex methylation specific PCR suitable for (early) detection of non-small cell lung cancer. Epigenetics. 2014;9(8):1138-1148.

13. Harden SV, Tokumaru Y, Westra WH, et al. Gene promoter hypermethylation in tumors and lymph nodes of stage I lung cancer patients. Clin Cancer Res. 2003;9(4):1370-1375.

14. Müller HM, Widschwendter M. Methylated DNA as a possible screening marker for neoplastic disease in several body fluids. Expert Rev Mol Diagn. 2003;3(4):443-458.

15. Esteller M, Sanchez-Cespedes M, Rosell R, Sidransky D, Baylin SB, Herman JG. Detection of aberrant promoter hypermethylation of tumor suppressor genes in serum DNA from non-small cell lung cancer patients. Cancer Res. 1999;59(1):67-70.

16. Hoque MO, Begum S, Topaloglu O, et al. Quantitative detection of promoter hypermethylation of multiple genes in the tumor, urine and serum DNA of patients with renal cancer. Cancer Res. 2004;64(15):5511-5517.

17. Ibanez de Caceres I, Battagli C, Esteller M, et al. Tumor cell-specific $B R C A 1$ and RASSF1A hypermethylation in serum, plasma and peritoneal fluid from ovarian cancer patients. Cancer Res. 2004;64(18):6476-6481.

18. Andreeva AV, Kutuzov MA. Cadherin 13 in cancer. Genes Chromosomes Cancer. 2010;49(9):775-790.

19. Wu LS, Qian JY, Wang M, Yang H. Identifying the role of Wilms tumor 1 associated protein in cancer prediction using integrative genomic analyses. Mol Med Rep. 2016;14(3):2823-2831.

20. Gu L, Zhao T, Lu XL, Qin GY. Identification of epigenetic aberrant promoter methylation of p16INK4A in serum for non-small cell lung cancer early diagnosis. J Med Res. 2013;42:163-166.

21. Zhao Y, Zhou H, Ma K, et al. Abnormal methylation of seven genes and their associations with clinical characteristics in early stage nonsmall cell lung cancer. Oncol Lett. 2013;5(4):1211-1218.

22. Morán A, Fernández-Marcelo T, Carro J, et al. Methylation profiling in non-small cell lung cancer: Clinical implications. Int J Oncol. 2012;40(3):739-746.

23. Zhai X, Li SJ. Methylation of RASSF1A and CDH13 genes in individualized chemotherapy for patients with non-small cell lung cancer. Asian Pac J Cancer Prev. 2014;15(12):4925-4928.

24. Pastuszak-Lewandoska D, Kordiak J, Antczak A, et al. Expression level and methylation status of three tumor suppressor genes, DLEC1, ITGA9 and $M L H 1$, in non-small cell lung cancer. Med Oncol. 2016;33(7):75.

25. Zhang $Y$, Wang $R$, Song $H$, et al. Methylation of multiple genes as a candidate biomarker in non-small cell lung cancer. Cancer Lett. 2011;303(1):21-28.

26. Fischer JR, Ohnmacht $\mathrm{U}$, Rieger $\mathrm{N}$, et al. Prognostic significance of RASSF1A promoter methylation on survival of non-small cell lung cancer patients treated with gemcitabine. Lung Cancer. 2007;56(1): 115-123.

27. Wang J, Wang B, Chen X, Bi J. The prognostic value of RASSF1A promoter hypermethylation in non-small cell lung carcinoma: A systematic review and meta-analysis. Carcinogenesis. 2011;32(3):411-416.

28. Li W, Deng J, Tang JX. Combined effects methylation of FHIT, RASSF1A and RARbeta genes on non-small cell lung cancer in the Chinese population. Asian Pac J Cancer Prev. 2014;15(13):5233-5237. 